\title{
Patient profile of patients attending to emergency department of a tertiary neurological and neurosurgical hospital of Nepal: One year experience.
}

\author{
Rashmi Shrestha ${ }^{1}$, Rachana Nakarmi ${ }^{2}$, Ritesh Luitel ${ }^{3}$, Subodh Sharma Paudel ${ }^{3}$, Pratyush Shrestha ${ }^{4}$ \\ ${ }^{1}$ Staff Nurse, ${ }^{2}$ Public Health Officer, ${ }^{3}$ Medical Officer, ${ }^{4}$ Associate Professor (Neurosurgery), Upendra Devkota Memorial- \\ National Institute of Neurological and Allied Sciences, Kathmandu, Nepal.
}

Received: June 15, 2020

Accepted: August 03, 2020

Published: September 1, 2020

Cite this paper:

Shrestha R, Nakarmi R, Luitel R, Paudel SS, Shrestha P. Patient profile of patients attending to emergency department of a tertiary neurological and neurosurgical hospital of Nepal: One year experience. Journal of Brain and Spine Foundation Nepal. 2020;1(1):20-24.

Correspondence:

Rashmi Shrestha

Staff Nurse

Emergency Department,

Upendra Devkota Memorial-National Institute of Neurological and Allied Sciences, Kathmandu, Nepal.

Email: shrestharashmi55@gmail.com

ORCID: https://orcid.org/0000-0001-8622-0693

\begin{abstract}
:
Introduction: Neurological emergencies are life threatening conditions that arise frequently and have devastating results if not diagnosed and treated quickly with high rates of neurological mortality and morbidity. Being a tertiary neurological center, Upendra Devkota Memorial National Institute of Neurological and Allied Science is a major referral center for neurological diseases. The objective of this study is to assess the types and number of diseases that present to the emergency department of a tertiary neurological center. Methods: This is a retrospective study conducted in emergency department of national neurosurgical/neurological referral hospital in Kathmandu, from Oct 2018 to Sept 2019. Clinico-epidemiological details of the patients were noted. Results: The total number of patients presenting to the emergency in one year period were 2995 . $58.33 \%$ were males and $41.67 \%$ were females with male to female ratio of 1:1.4. Majority of the patients $(24.91 \%)$ were above 60 years of age. Trauma $(26.08 \%)$ was the major admissions followed by stroke $(25.71 \%)$ and headache (11.79\%). The majority of trauma were road traffic accident $(43.02 \%)$ followed by fall injury $(29.83 \%)$ and physical assault $(18.96 \%)$. Out of the stroke cases, $51.68 \%$ were ischemic followed by hemorrhagic stroke $44.55 \%$ and transient ischemic attack $(3.77 \%)$. One thousand eight hundred and ten people were admitted. Conclusion: The study presents an overview of the patients presenting as neurological emergency. It helps to better plan and devise resources and system in a neurosurgical emergency.
\end{abstract}

Key words: Emergency, Headache, Stroke, Trauma

\section{Introduction:}

Neurologic emergency is a life-threatening condition where patients are usually left with poor functional recovery unless treated promptly. Neurologic emergencies arise frequently and if not diagnosed and treated quickly, can have devastating results with high rates of long-term disability and death. ${ }^{1}$ Acute neurological illness is one of the common causes for admission in the emergency. There are number of such conditions and it is worthwhile to understand what one needs to do when someone develops neurological emergencies. Emergency care in neurology requires a response within minutes or hours often to patients who are unconscious and require prompt support or interventions. $^{2}$ Upendra Devkota Memorial National Institute of Neurological and Allied Science (UDM- 
NINAS) is a national neurosurgical/neurological referral center of Nepal. In this study we tried to assess the clinicepidemiological profiles of patient attending to UDMNINAS.

\section{Methods:}

A retrospective review of the data of admission records from the emergency department of UDM-NINAS was done from October 2018 to September 2019. UDMNINAS is a tertiary care center and national neurological/neurosurgical referral center of our country, exclusively dedicated to public-health assistance. The clinical neurological staff of the hospital are on call 24 hours a day, 7 days a week. In this study we tried to analyze the admission patterns of patients who sought neurological emergency services from UDM-NINAS during the study period. Records were retrieved from the register and computer of emergency departments and data were evaluated on sociodemographic profile (age, gender, region, race/ethnicity and nationality), diagnosis and outcome (Discharge, Hospital admission and Death). Only deaths that occurred in the ER were included. Patients with incomplete records or lost records and those who were sent to out-patient department after initial evaluation were excluded from the study.

All patients were initially assessed by emergency staffs (nurses, paramedics and house officers) and any emergency care required were provided simultaneously while keeping the on-call consultants informed about the cases. When necessary, laboratory and imaging tests were sent which included brain computed tomography (CT), brain magnetic resonance imaging (MRI), X-ray, Electroencephalogram (EEG) etc.

\section{Results:}

Altogether 2995 patients sought for emergency services in the emergency department of UDM-NINAS in the study period. Out of 2995, 1248 (41.67\%) were female and $1747(58.33 \%)$ were male with the ratio of $1: 1.4$ (Figure 1). The age distribution of the patients attending to emergency services were tabulated in Table 1. Among the patients, majority of them $83.20 \%$ were from Hilly region, $15.42 \%$ from terai, $1.05 \%$ from himalayan region and $0.33 \%$ were foreigners.

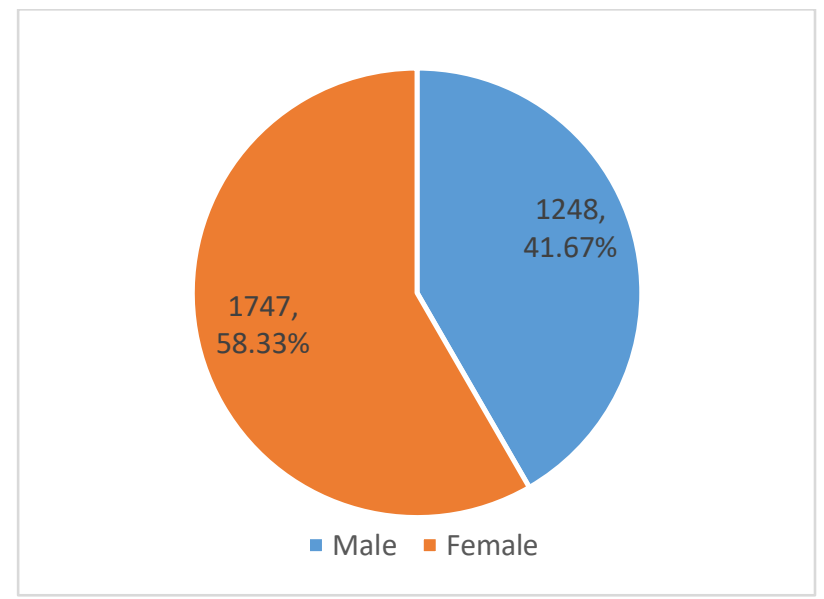

Figure 1: Gender distribution

Trauma (Cranial, Spinal and Polytrauma) was the most common presentation to our emergency services (781, $26.08 \%$ ) followed by sroke $(770,25.71 \%)$ and headache (353, 11.79\%) (Table 2). Regarding trauma, road traffic accidents were highest in number (43.02\%) followed by fall injury $29.83 \%$. Similarly, physical assault was found to be $18.96 \%$ and about $8.19 \%$ were others such as electric shock, cut injury etc. (Figure 2). Amongst trauma, majority $(66.97 \%)$ were male. Similarly, road traffic accidents (28.79\%), physical assault (31.03\%) and other injuries $(45.90 \%)$ were seen maximum in 20 29 years age group whereas, fall injury $(25.87 \%)$ in $0-9$ years age group.

Table 1. Age distribution of the patients

\begin{tabular}{llll} 
S.N & Age Group & Number & Percentage \\
\hline 1 & $0-10$ Years & 141 & $4.71 \%$ \\
2 & 10-19 Years & 307 & $10.25 \%$ \\
3 & 20-29 Years & 503 & $16.79 \%$ \\
4 & 30-39 Years & 445 & $14.86 \%$ \\
5 & 40-49 Years & 432 & $14.42 \%$ \\
6 & 50-59 Years & 421 & $14.06 \%$ \\
7 & $>60$ Years & 746 & $24.91 \%$ \\
\hline
\end{tabular}


Out of the stroke cases, ischemic stroke (51.68\%) was found to be in highest number followed by hemorrhagic stroke (44.55\%) and about $3.77 \%$ was transient ischemic attack (Table 1). Even though the maximum number of ischemic stroke was seen in above 60 years $(56.70 \%)$, stroke was also seen in the patients below 40 years which accounts $15.72 \%$. Out of the total ischemic stroke, emergency thrombolysis was done in $2.83 \%$. Regarding hemorrhagic stroke, putaminal bleed was found to be in highest number (33\%). Space occupying lesion was further categorized as tumor (brain and spine) $87 \%$, brain abscess 7\%, neurocysticercosis 5\%, and tuberculoma $1 \%$.



Figure 2: Mode of Injury

Out of the total patients, $1810(60.43 \%)$ of the patients got admitted, 263 (8.78\%) got referred to other hospitals for non-neurological conditions, 47 (1.57\%) left against medical advice, $11(0.37 \%)$ died in the emergency despite every attempt, $10(0.33 \%)$ were brought dead and $854(28.51 \%)$ were discharged from emergency.

\section{Discussion:}

With advancements of technologies and new methods emergency medicine has emerged as an important medical specialty. Patients present to emergency department with life threatening conditions and hence should be evaluated properly and promptly with trained
Neurological emergencies carry a high burden. These conditions can be difficult to diagnose, and delay in recognition and treatment can have devastating results. ${ }^{1}$ In recent years, improved time-dependent treatments for patients with acute neurological emergencies have been developed, increasing the importance of a rapid and accurate diagnosis. ${ }^{3}$

This study has demonstrated that 2995 sought for emergency services in our center. Being a neurological tertiary center, this center even receives non neurological emergencies which accounted for $8.78 \%$ of the total emergencies seen in our center. There were $58.13 \%$ male with a M:F ratio of 1:1.4. A study from South Nigeria also noted male: female ratios of $1.3: 1 .{ }^{4}$ In this study, majority of the patient were $>60$ years of age (24.91\%) followed by $16.79 \%$ under $20-29$ years. An Indian study reveals most victims were from $15-30$ years (32\%) followed by $30-35$ years (24\%) age group. ${ }^{5}$

Table 2: Diagnosis of patients presenting to emergency

\begin{tabular}{|c|c|c|c|}
\hline & Diagnosis & Frequency & Percentage \\
\hline 1 & Trauma & 781 & 26.08 \\
\hline 2 & $\begin{array}{l}\text { Stroke } \\
\text { Ischemic } \\
\text { Hemorrhagic } \\
\text { TIA }\end{array}$ & $\begin{array}{l}770 \\
398 \\
233 \\
29\end{array}$ & $\begin{array}{r}25.71 \\
51.68 \\
44.55 \\
3.77\end{array}$ \\
\hline 3 & Headache & 353 & 11.79 \\
\hline 4 & Seizures & 192 & 6.41 \\
\hline 5 & $\begin{array}{l}\text { Space Occupying Lesions } \\
\text { Tumors } \\
\text { Brain abscess } \\
\text { Neurocysticercosis } \\
\text { Tuberculoma }\end{array}$ & $\begin{array}{r}113 \\
98 \\
8 \\
6 \\
1\end{array}$ & $\begin{array}{r}3.77 \\
87 \\
7 \\
5 \\
1\end{array}$ \\
\hline 6 & Others & 524 & 17.49 \\
\hline 7 & Non Neurological & 262 & 8.75 \\
\hline
\end{tabular}

manpower and adequate resources, the disease conditions should be identified as soon as possible and correct treatment should be started to improve the patient's prognosis. Neurological disorders are a common reason for admission to the emergency 
department and are associated with high morbidity and mortality. ${ }^{6}$ In this study, out of total patients, 10 $(0.33 \%)$ patients were brought dead. Other research shows 16 patients that were arrived dead in one of the neurological hospital in India. ${ }^{5}$ The most common neurological emergencies observed in our study were trauma $(26.08 \%)$ followed by stroke $(25.71 \%)$. A research done in US revealed, $61 \%$ were for cerebrovascular emergencies (stroke, transient ischaemic attack, and intracerebral haemorrhage). Other emergencies involved seizures, encephalopathy, migraine, syncope, vestibulopathy, transient global amnesia, and brain tumour, and each represented $6 \%$ or less of the total consultations. ${ }^{2}$ A descriptive study done in Africa showed $38.1 \%$ of the patients encountered had a mechanism of injury related to fall, motor vehicle accident $33.3 \%$ and assault $13.3 \%{ }^{7}$ A retrospective study from South Nigeria also reported that the commonest diagnoses of neurological patients attending to emergency department were stroke (52.5\%), meningoencephalitis (11.3\%) and hypertensive encephalopathy $(7 \%){ }^{4}$

Stroke is the fourth leading cause of death in the United States and is one of the most common causes of disability worldwide. About $85 \%$ of strokes are ischemic, resulting from diminished vascular supply to the brain. ${ }^{1}$ In this study, the majority of ischemic stroke was seen in above 60 age group (56.70\%), whereas it was also seen in the age below 40 years which accounts $15.72 \%$. In India, a retrospective study revealed about $10 \%$ to $15 \%$ of strokes occured in people below the age of 40 years. ${ }^{5}$ In our study $51.68 \%$ of cases of stroke were ischemic, $44.55 \%$ were hemorrhagic and $3.77 \%$ were transient ischemic attacks. A retrospective study done in neurology department of Institute of medicine, Nepal had observed 63\% ischemic stroke and 37\%hemorrhagic stroke in their series. ${ }^{8}$ Devkota et al. in their study also noticed $68.1 \%$ ischemic stroke and $31.9 \%$ hemorrhagic stroke. ${ }^{9}$ This study observed that males were moreprone to present with seizures than female. In India, a research done by Sahoo et al. shows seizure was more common among males (54\%), while unconsciousness was more common among females (24\%). ${ }^{5}$ A study by Lange et al. in 2011 from Brazil showed Cerebrovascular diseases $(42.69 \%)$, primary headache $(7.1 \%)$, and seizure disorder $(12 \%)$ were the commonest presentations to emergency department. ${ }^{6}$ In India, Seizure (51.5\%) was the most common emergency reported, followed by stroke (24\%) and unconsciousness (21\%). ${ }^{5}$

\section{Conclusions:}

The most common cases seen in our center was trauma followed by stroke. The most common modes of trauma seen was road traffic accident followed by fall injury and physical assaults. The most common cases of stoke was ischemic and amongst them $2.83 \%$ patients received emergent thrombolysis. About $60 \%$ of cases were admitted and $0.37 \%$ patients died despite all efforts. Thus, management of neurological cases as per an existing guidelines to provide a prompt and effective primary treatment and care is required to prevent long term disability and death.

\section{Acknowledgements:}

I would like to thank Upendra Devkota Memorial National Institute of Neurological and Allied Science for providing ethical clearance as well as their support in conducting this research.

\section{References:}

1. Kottapally M, Josephson SA. Common neurologic emergencies for non-neurologists: When minutes count. Cleve Clin J Med. 2016 Feb;83(2):116-26. https://doi: 10.3949/ccjm.83a.14121.

2. Stone K. When seconds count: tackling neurological emergencies. Lancet Neurol. 2009 Aug;8(8):702-3. https://doi: 10.1016/S1474-4422(09)70193-0.

3. Pope JV, Edlow JA. Avoiding misdiagnosis in patients 
with neurological emergencies. Emerg Med Int. 2012;2012:949275. https://doi: 10.1155/2012/949275.

4. Philip-Ephraim EE, Eyong KI, Oparah SK, Williams U, Udonwa NE, Gyuse AN, et al. Profile of neurologic emergencies at the accident and emergency department of a tertiary hospital in South Nigeria. J.Neurol.Sci.(Turk).2013;30(1):72-80. Available from: https://www.researchgate.net/publication/256138873_Pro file_of_Neurologic_Emergencies_At_The_Accident_Em ergency_Department_of_A_Tertiary_Hospital_in_South_ Nigeria.

5. Saddichha S, Saxena MK, Vibha $P$, Methuku $M$. Neurological emergencies in India-lessons learnt and strategies to improve outcomes. Neuroepidemiology. 2009;33(3):280-5. https://doi: 10.1159/000235640.

6. Lange Marcos C, Braatz Vera L, Tomiyoshi Carolina, Nóvak Felipe M., Fernandes Artur F, Zamproni Laura N, et al . Neurological diagnoses in the emergency room: differences between younger and older patients. Arq. Neuro-Psiquiatr. $\quad 2011 \quad$ Apr ;69(2a):212-6. https://doi.org/10.1590/S0004-282X2011000200014.

7. John K, Faye F, Belue R. A descriptive study of trauma cases encountered in the Grand M'Bour Hospital Emergency Department in Senegal. Pan Afr Med J. 2019 Jan 7;32:9.https:// doi: 10.11604/pamj.2019.32.9.14550.

8. Oli KK, Agarwal JP. Critical review of stroke. J Inst Med 2001; 23:68- 71 .

9. Devkota KC, Thapamagar SB, Malla S. Retrospective analysis of stroke and its risk factors at Nepal Medical College Teaching Hospital. Nepal Med Coll J 2006;8:269'75. Available from: https://pdfs.semanticscholar.org/aac4/db07a6908742160f b41b3eec58cd44a08650.pdf. 